\title{
Testosterone monitoring for men with advanced prostate cancer: Review of current practices and a survey of Canadian physicians
}

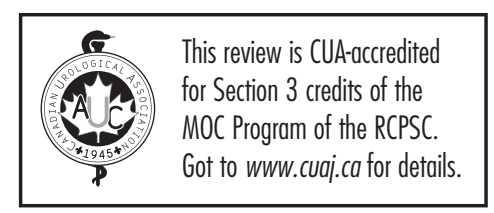

\section{Bobby Shayegan, MD'; Frédéric Pouliot, MD, PhD²; Alan So, MD³; John Fernandes, MD'; Joseph Macri, PhD}

'Division of Urology, Department of Surgery, McMaster University, Hamilton, ON; ${ }^{2}$ Division of Urology, Department of Surgery, Université Laval, Quebec, QC; ${ }^{3}$ Department of Urologic Sciences, University of British Columbia, Vancouver, BC; ${ }^{2}$ Department of Pathology and Molecular Medicine, McMaster University, Hamilton, ON

Cite as: Can Urol Assoc J 2017;11 (6):204-9. http://dx.doi.org/10.5489/cuaj.4539

See related commentary on page 210.

\section{Abstract}

Androgen-deprivation therapy (ADT) is a standard of care in the treatment of advanced prostate cancer; however, testosterone monitoring practices for men undergoing ADT vary across Canada. Although a testosterone level of $1.7 \mathrm{nmol} / \mathrm{L}$ or lower has historically been defined as the accepted castrate level, newer assays with improved sensitivity have shown that both medical and surgical castration can suppress testosterone levels to below $0.7 \mathrm{nmol} / \mathrm{L}$. This review explores the evidence supporting a redefinition of the castrate testosterone level as $0.7 \mathrm{nmol} / \mathrm{L}$ or lower, and presents results of a survey of testosterone monitoring practices among 153 Canadian urologists, uro-oncologists, and radiation oncologists who manage the treatment of men with hormone-sensitive prostate cancer.

\section{Introduction}

Since the report by Huggins and Hodges in 1941 showing that prostate cancer cells rely on androgens to grow and survive, castration has been the standard therapeutic approach for patients with advanced prostate cancer. ${ }^{1}$ Surgical castration, or bilateral orchiectomy, was the gold standard for androgen deprivation in patients with prostate cancer for several decades, until the 1980s, when luteinizing hormone-releasing hormone (LHRH) agonists became available. Conventional LHRH agonists currently available on the market include leuprolide acetate, buserelin, goserelin, and triptorelin, each available in depot formulations requiring monthly, three-monthly, four-monthly, or longer-duration injections. More recently, the LHRH antagonist degarelix became available with a monthly depot.

Historically, the efficacy of androgen-deprivation therapies (ADT) has been assessed by measuring levels of circulating testosterone, with castration defined as a testosterone level below $1.7 \mathrm{nmol} / \mathrm{L}$. This level was determined based on methodological considerations and the sensitivity of assays that were available during the early 2000s. ${ }^{2}$ Early serum testosterone assays used double-isotope-derivative dilution with a thin-layer chromatography modification and were limited in their accuracy and sensitivity. ${ }^{3-5}$ The limits of measurement imposed by these assays led to the target testosterone suppression definition of less than $1.7 \mathrm{nmol} / \mathrm{L} ;{ }^{4,6}$ however, more recent studies measuring serum testosterone levels after surgical castration with the use of more modern techniques, using improved radioimmunoassay (RIA) and chemiluminescent immunoassay (CLIA) and mass spectrometry (MS) methods, have reported mean testosterone levels as low as $0.003 \mathrm{nmol} / \mathrm{L}$. ${ }^{4,7-11}$ Several studies since the early 1990s have therefore challenged the outdated benchmark of $1.7 \mathrm{nmol} / \mathrm{L}$ and recommended revisiting the definition, with many suggesting a new benchmark of $0.7 \mathrm{nmol} / \mathrm{L}$., ${ }^{42-14}$

In light of conflicting opinion on the ideal goal for suppression of serum testosterone in men with advanced cancer, we conducted a survey of Canadian urologists, uro-oncologists, and radiation oncologists to gain a better understanding of their testosterone monitoring practices when managing men with hormone-sensitive prostate cancer. Survey participants were selected from a private database of Canadian healthcare providers who have participated in educational, advisory, and editorial activities related to the treatment of prostate cancer. Of the 619 physicians who were sent the survey via email, 153 physicians completed the online survey, which included questions about frequency of testosterone monitoring, how castrate testosterone levels are defined in their centre, and response to testosterone levels that rise above this threshold. They were also questioned about the type and sensitivity of testosterone assay used by their centre. The majority of respondents were urologists $(63 \%)$, followed by radiation oncologists (23\%) and uro-oncologists (14\%). It should be noted that comparisons of response rates are purely descriptive, as no statistical analysis of the results was performed. 


\section{Current testosterone monitoring practices}

In our survey of Canadian specialists, $42.5 \%$ of the survey respondents indicated that they monitor testosterone "regularly," while $28.8 \%$ responded that they "always" monitor testosterone and $5.2 \%$ indicated that they "never" monitor testosterone at the initiation of continuous ADT in their patients with advanced prostate cancer. Practices with respect to testosterone monitoring were generally similar among the three specialties; however, radiation oncologists and urooncologists were more likely to "always" monitor testosterone $(45.5 \%$ and $40 \%$, respectively) than urologists $(20 \%)$, while urologists were more likely to monitor "regularly" (50\%) (Fig. 1A). Following initiation of ADT, for men with expected prostate-specific antigen (PSA) levels, $40.5 \%$ of all respondents would monitor testosterone before each $\mathrm{LHRH}$ injection and $35.3 \%$ would monitor once a year; the remaining respondents would rarely $(17 \%)$ or never $(6.5 \%)$ monitor. Given this situation, urologists would be slightly more inclined than their radiation oncologist and uro-oncologist colleagues to monitor testosterone once a year $(39 \%, 27 \%$, and $25 \%$, respectively) and less inclined to monitor prior to each $\mathrm{LHRH}$ injection (36\%, 55\%, and 55\%, respectively) (Fig. 1B).

Current guidelines have not reached a consensus regarding the ideal testosterone suppression goal for men with prostate cancer. The National Comprehensive Cancer Network (NCCN) and the European Association of Urology (EAU) guidelines use a cutoff of $1.7 \mathrm{nmol} / \mathrm{L},{ }^{15,16}$ while the American Society of Clinical Oncology (ASCO $)^{17}$ and the Canadian Urological Association (CUA) ${ }^{18}$ have yet to specify a testosterone suppression goal. Our survey of Canadian urologists, uro-oncologists, and radiation oncologists revealed that a testosterone threshold of $0.7 \mathrm{nmol} / \mathrm{L}$ is most commonly used $(73.2 \%)$, while a lower percentage use a threshold of $1.7 \mathrm{nmol} / \mathrm{L}(21.6 \%)$ and $5.2 \%$ do not have a specific testosterone target at all.

Even using the standard definition for castration testosterone level of $1.7 \mathrm{nmol} / \mathrm{L}$, a significant proportion of patients on LHRH agonists (2-12.5\%) do not achieve this level, ${ }^{19-22}$ and an even greater proportion (13-37.5\%) fail to achieve the more stringent testosterone level of $0.7 \mathrm{nmol} / \mathrm{L}^{19,20,22,23}$ In a population-based series of 1442 men in Quebec undergoing LHRH agonist therapy with curative radiation therapy, the risk of any breakthrough during 2334 person-years of followup was $4.5 \%$ when using a cutoff of $1.7 \mathrm{nmol} / \mathrm{L}$ and $25 \%$ when using a cutoff of $0.7 \mathrm{nmol} / \mathrm{L} .{ }^{24}$ Using clinical data from chart reviews or existing databases, Pickles et al analyzed breakthrough rates above castrate levels of testosterone in men undergoing adjuvant LHRH agonist therapy with curative radiation therapy in British Columbia. ${ }^{25}$ Among 2196 patients treated with one of four LHRH agonists (goserelin, leuprolide IM, buserelin, and leuprolide SC), the risk of a testosterone breakthrough per LHRH injection was 3.2\% using a cutoff of $1.1 \mathrm{nmol} / \mathrm{L}$ and $2.2 \%$ for a cutoff of 1.7 $\mathrm{nmol} / \mathrm{L}$. The breakthrough rates reported in this study were lower than those in other studies, as Pickles et al restricted their analysis to data that were obtained from testosterone assays that have been shown to be more accurate at low levels; other series have not done this and may therefore have overestimated the true rate of testosterone breakthrough. ${ }^{25}$

\section{Clinical significance of testosterone suppression}

Whether breakthroughs in clinical testosterone impact disease progression has been evaluated in several studies. In
A

At the initiation of continuous ADT, how do you approach testosterone monitoring?

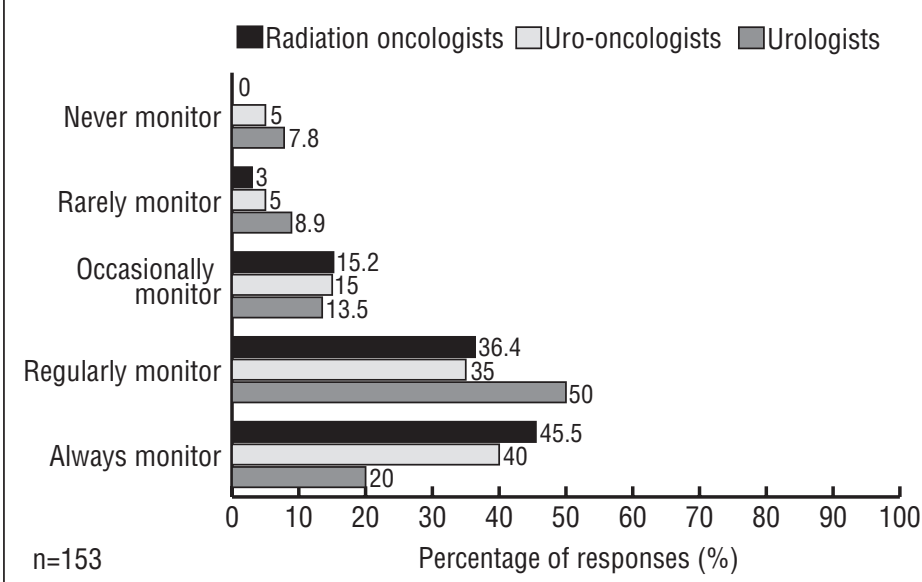

B

With what requency do you monitor testosterone, assuming PSA is behaving as you would expect?

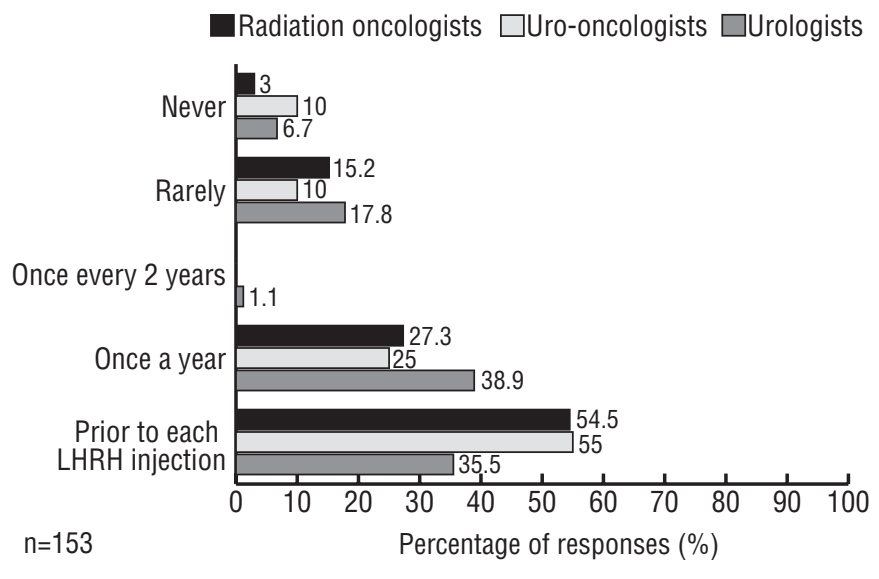

Fig. 1. Approach to testosterone monitoring among Canadian urologists, radiation oncologists, and uro-oncologists $\boldsymbol{A}$ ) at the initiation of continuous androgendeprivation therapy (ADT); and $\boldsymbol{B}$ ) with ongoing treatment, assuming that prostate-specific antigen (PSA) levels are as expected. LHRH: luteinizing hormonereleasing hormone. 
Shayegan et al.

the Quebec population-based series of men undergoing LHRH agonist therapy with curative radiation therapy, ${ }^{24}$ multivariate analysis adjusting for clinical stage, pretreatment PSA, Gleason score, age, and smoking did not reveal an association between testosterone breakthrough and either biochemical failure or survival; however, subgroup analysis showed a trend toward inferior five-year biochemical failure in those with testosterone breakthroughs of greater than $1.7 \mathrm{nmol} / \mathrm{L}$ vs. those without (adjusted hazard ratio [HR] 1.74 [0.98-3.10]). ${ }^{24}$ In the study by Pickles et al, of 2290 patients in British Columbia with localized prostate cancer treated with curative radiation therapy, the overall five-year rate of PSA failure-free survival was $82 \%$, but fell to $72 \%$ in those with testosterone breakthrough levels of 1.1-1.74 $\mathrm{nmol} / \mathrm{L}(\mathrm{p}=0.03) .^{26,27}$ Taken together, these data suggest that inadequate early testosterone suppression negatively impacts downstream biochemical control; ${ }^{24,26,27}$ however, only breakthrough levels above $1.7 \mathrm{nmol} / \mathrm{L}$ appear to be associated with higher rates of biochemical failure. ${ }^{24}$

Several studies have shown a correlation between adequate testosterone suppression and freedom from progression to castrate-resistant disease. ${ }^{13,28}$ Among 73 patients with non-metastatic prostate cancer receiving three-month depots of $\mathrm{LHRH}$ agonist, 41 patients had progressed to castrate-resistant prostate cancer (CRPC) after a median followup of 51 months. ${ }^{13}$ Testosterone breakthroughs above $1.7 \mathrm{nmol} / \mathrm{L}$ and $1.1 \mathrm{nmol} / \mathrm{L}$ were found to be predictors of progression to CRPC. Mean survival free of androgen-independent progression was 88 months in patients with testosterone breakthroughs above $1.1 \mathrm{nmol} / \mathrm{L}$, compared with 137 months in those without breakthrough increases $(p<0.03) .{ }^{13}$ In a prospective cohort series of 32 patients undergoing ADT with LHRH agonist or antagonist at a tertiary centre from 2006-2011, patients with a nine-month serum testosterone level of less than 1.1 $\mathrm{nmol} / \mathrm{L}$ had a significantly increased time to CRPC compared with patients with testosterone levels between 1.1 and 1.7 $\mathrm{nmol} / \mathrm{L}$ ( $\mathrm{p}=0.001$; median progression-free survival [PFS] 33.1 months). ${ }^{28}$ Patients with first-year mean testosterone levels below $1.1 \mathrm{nmol} / \mathrm{L}$ also had a significantly longer time to CRPC than those with levels between 1.1 and $1.7 \mathrm{nmol} / \mathrm{L}(p=0.05$, median PFS 33.1 months). ${ }^{28}$

The NCIC-PR7 trial of 1386 men with non-metastatic prostate cancer and PSA biochemical failure following radiotherapy (primary or salvage post-prostatectomy) showed that intermittent ADT is a viable option for men with non-metastatic prostate cancer. ${ }^{29}$ The continuous therapy arm of the NCIC-PR7 trial comprised 626 evaluable patients receiving ADT for a median of eight years, which provided an opportunity for Klotz and colleagues to assess the relation between nadir testosterone level and disease progression. ${ }^{30}$ This analysis included patients from the continuous arm of the NCICPR7 trial who had at least three testosterone levels recorded during the first year of the study. Patients were classified into one of three groups according to their testosterone level: 0.7 $\mathrm{nmol} / \mathrm{L}$ or lower $(53 \%), 0.7-1.7 \mathrm{nmol} / \mathrm{L}(42 \%)$, or higher than $1.7 \mathrm{nmol} / \mathrm{L}$ (5\%). Time to CRPC differed significantly among the three testosterone groups. Patients who did not achieve a testosterone level below $0.7 \mathrm{nmol} / \mathrm{L}$ had a significantly higher risk of developing CRPC than those who achieved a testosterone level below $0.7 \mathrm{nmol} / \mathrm{L}$ (HR 1.62 for testosterone $0.7-1.7$ $\mathrm{nmol} / \mathrm{L} ; \mathrm{HR} 1.90$ for testosterone $1.7 \mathrm{nmol} / \mathrm{L}$ or higher) (Fig. 2). Patients with a minimum testosterone level higher than 0.7 $\mathrm{nmol} / \mathrm{L}$ also had a significantly higher risk of dying as a result of their disease (HR 2.08 for testosterone $0.7-1.7 \mathrm{nmol} / \mathrm{L}$; HR 2.93 for testosterone $1.7 \mathrm{nmol} / \mathrm{L}$ or higher). A post-hoc analysis was also recently conducted of the ICELAND study - a large, multicentre, European study demonstrating similar efficacy and tolerability between continuous and intermittent ADT with leuprolide acetate (Eligard) in non-metastatic prostate cancer. ${ }^{31}$ Neither time to PSA progression nor causespecific survival was influenced by testosterone levels during the first year of treatment. In contrast to the NCIC-PR7 trial, which allowed treatment with orchiectomy or any LHRH analogue, the ICELAND study only allowed treatment with leuprolide acetate, which may account for the disparity in results. ${ }^{31}$ It is noteworthy that median followup was half that of the NCIC-PR7 trial, which could explain the differences observed between the two studies.

Another trial of 206 patients with metastatic prostate cancer randomly assigned patients to a monthly or three-month depot of LHRH agonist along with an androgen receptor antagonist. ${ }^{32} \mathrm{~A}$ testosterone level of $0.9 \mathrm{nmol} / \mathrm{L}$ or less one month after initiating ADT, was associated with a longer time to CRPC than testosterone levels higher than $0.9 \mathrm{nmol} / \mathrm{L}$ (19.1 vs. 14.6 months; $p=0.0004)$. Likewise, six months after initiating ADT, a testosterone level of $0.7 \mathrm{nmol} / \mathrm{L}$ or lower was associated with a longer time to CRPC than testosterone levels of $0.7 \mathrm{nmol} / \mathrm{L}$ or higher. ${ }^{32}$

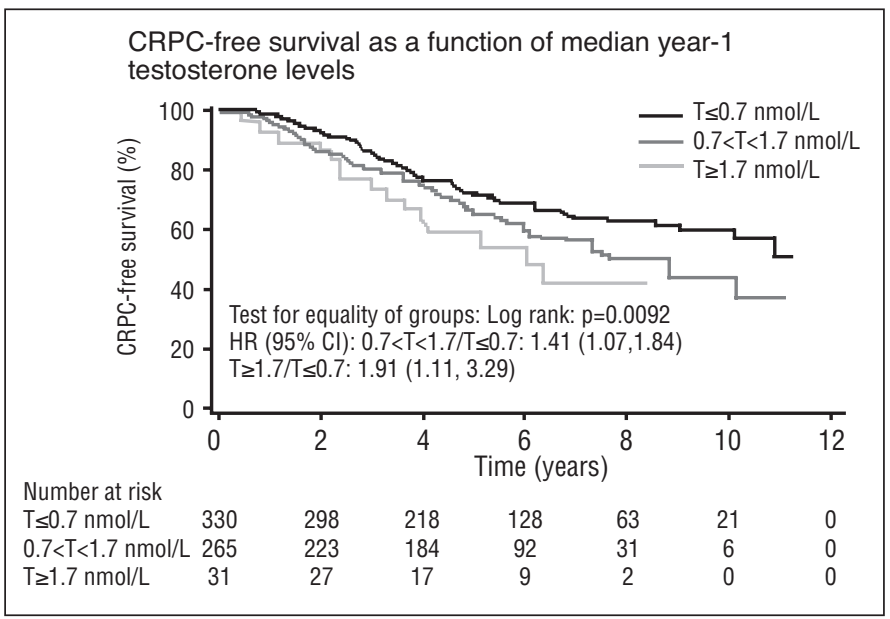

Fig. 2. Time to castrate-resistant prostate cancer (CRPC) by nadir testosterone (T) within the first year of androgen-deprivation therapy in a secondary analysis of the PR-7 trial. ${ }^{30} \mathrm{Cl}$ : confidence interval; HR: hazard ratio. 
These studies suggest that a nadir serum testosterone level of less than $0.7 \mathrm{nmol} / \mathrm{L}$ while on continuous ADT therapy correlates with improved prognosis. It is therefore reasonable to recommend assaying serum testosterone levels regularly in these patients, with ADT modified accordingly to ensure that testosterone levels of less than $0.7 \mathrm{nmol} / \mathrm{L}$ are achieved. It should be noted, however, that there is currently a lack of evidence that switching therapies improves survival. For the majority of respondents to our survey, a testosterone level above the threshold value, assuming PSA levels were as expected, would prompt a duplicate testosterone assay in three months $(48.4 \%)$. Others would re-assay the testosterone levels immediately $(10.5 \%)$, immediately switch the patient to another LHRH agonist (7.2\%), immediately switch the patient to an $\mathrm{LHRH}$ antagonist $(5.2 \%)$, or have the patient undergo surgical orchiectomy $(0.7 \%) ; 18.3 \%$ would do nothing.

Consistently lower testosterone levels have also been associated with a survival advantage in prostate cancer. In a prospective evaluation of 153 patients treated with an $\mathrm{LHRH}$ agonist for six months, multivariate analysis did not reveal an association between serum testosterone levels and either time to progression or overall survival; ${ }^{33}$ however, serum testosterone levels less than $0.7 \mathrm{nmol} / \mathrm{L}$ were significantly associated with a lower risk of death $(p=0.02)$. Because only 25 patients achieved a testosterone level below $0.7 \mathrm{nmol} / \mathrm{L}$, a receiveroperating characteristic (ROC) curve was used to determine a cutoff and distinguish between patients who would ultimately die and those who would not. A testosterone value of 1.0 $\mathrm{nmol} / \mathrm{L}$ was determined to offer the best overall sensitivity and specificity, and the 56 patients who attained testosterone levels of $1.0 \mathrm{nmol} / \mathrm{L}$ or less after six months of LHRH treatment had improved survival compared with the 97 patients who did not $(p=0.03) .^{33}$ The phase 3 COU-AA-301 study of patients with metastatic CRPC experiencing disease progression after chemotherapy showed increased rates of survival with the combination of abiraterone acetate and prednisone compared with prednisone alone. ${ }^{34}$ Retrospective analysis of the COU-AA-301 showed an increase in median survival from the lowest to the highest quartile of testosterone level, regardless of treatment arm. ${ }^{35}$

In a single-centre analysis of data from 96 men with locally advanced or metastatic prostate cancer treated with surgical castration, LHRH agonist, or anti-androgen, the lowest quartile of serum testosterone levels during ADT significantly predicted better overall survival and survival from castration resistance. ${ }^{36}$

\section{Measurement of serum testosterone}

Despite recent diagnostic advances and a call for improved diagnostic performance, uncertainty exists regarding measurement accuracy at very low testosterone levels using commercial assay techniques. The ability to provide increased analytical performance is typically at odds with the requirement to offer a high-throughput routine diagnostic test. Immunoassays and mass spectrometry are the two main methods used in measuring testosterone today. The latter is not routinely used in clinical practice due to higher cost, decreased throughput, and limited availability.

\section{Immunoassays}

The vast majority of total testosterone assays used in diagnostic laboratories are immunoassays. In general, these assays are very good with respect to analytical performance. They are robust, easily automated, and relatively easy to implement and operate in virtually any laboratory.

Immunoassays used for total testosterone measurement include RIA and CLIA. Because of the decreased availability of commercial diagnostic kits and the safety issues surrounding the use of radioisotopes, significantly fewer laboratories use RIA to measure total testosterone compared with CLIA. There are currently at least eight major manufacturers of total testosterone immunoassays that are used worldwide. Although there continues to be incremental improvements in the performance of these assays, the sensitivity and specificity, in particular for the low and high range of testosterone concentrations, remain insufficient for a variety of clinical applications. ${ }^{37}$ In addition, as is often the case for immunoassays, there is poor comparability between total testosterone results obtained from different commercial testosterone assays. The analytical difficulties, particularly with determining low testosterone concentrations, are in part due to interferences from serum proteins and crossreactivity with other steroid hormones. ${ }^{37,38}$

\section{Mass spectrometry}

As an analytical technique, MS has few rivals. It is often considered the gold standard or definitive method from which all other analytical techniques are measured. The use of MS in the clinical laboratory is ever-increasing, driven by the clinical demand for improved sensitivity and specificity of diagnostic tests. Industry had responded by developing MS instruments that are increasingly amenable to diagnostic laboratories rather than exclusively for research purposes. These include design improvements that facilitate automation and sample handling, ability to directly interface with laboratory information systems, and software packages that allow the instruments to be operated without significant training.

With respect to measuring low total testosterone levels, MS is analytically superior to immunoassay platforms because it can overcome the interferences and limitations associated with antibody-based tests. ${ }^{39}$ This is accomplished by direct coupling of MS instruments to a chromatography platform via an interface.

With the exception of the use of MS instruments in microbiology, MS platforms have yet to be developed to the point 
Shayegan et al.

where they are considered "plug and play." As such, the use of MS for serum testosterone measurement is limited to relatively few laboratories operating in support of large medical centres or as a regional reference laboratory. Implementation and routine operation of MS instruments require substantial capital investment in instrumentation and infrastructure, as well as significant technical expertise and experience.

In our survey of Canadian urologists, uro-oncologists, and radiation oncologists, the majority of respondents (79\%) were unable to specify which method of testosterone assay is used by their lab or centre (Fig. 3A). Of those who did know which testosterone assay method was used in their centre, 55\% indicated that RIA is used, $32 \%$ indicated that CLIA is used, and $13 \%$ indicated that MS is used. The lower limit of testosterone detection varied among the various centres, with the most common limit being $0.7 \mathrm{nmol} / \mathrm{L}(27.7 \%)$, followed by $0.3 \mathrm{nmol} / \mathrm{L}(22.3 \%$ ) (Fig. 3B). More than onethird of respondents $(31.8 \%)$ did not know the lower limit of testosterone detection of the assay used by their centre.

\section{Conclusion}

Lower testosterone levels have been shown to correlate with better freedom from CRPC and subsequent death. Moreover, breakthrough testosterone levels higher than $1.7 \mathrm{nmol} / \mathrm{L}$ during therapy may be associated with higher rates of biochemical failure. As such, prescribers of LHRH agonists should periodically assess testosterone levels to ensure that an adequate level of castration has been achieved. According to our survey of Canadian urologists, uro-oncologists, and radiation oncolo-

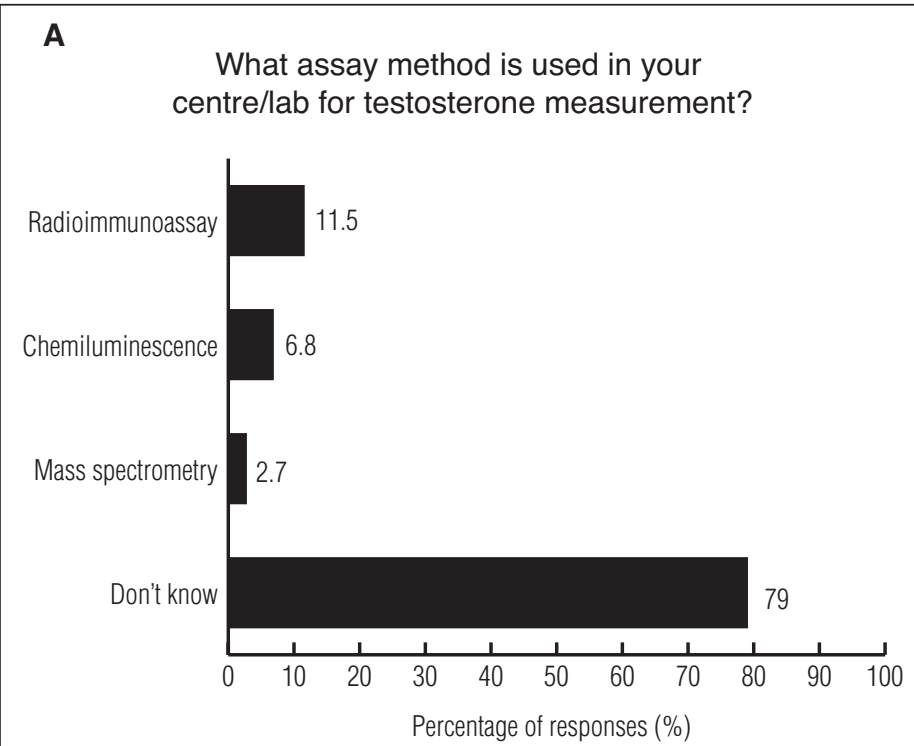

$n=148$ gists, approximately two-thirds are monitoring testosterone

regularly — either yearly or prior to each LHRH injection. We suggest that testosterone be measured at the same time as PSA, every three to six months, preferably using electro-CLIA or MS assays with detection limits well below $0.7 \mathrm{nmol} / \mathrm{L}$. A change in therapy may be considered if testosterone levels remain above $0.7 \mathrm{nmol} / \mathrm{L}$ on two or more occasions within a year; however, additional studies are needed to determine whether switching therapies improves prognosis.

While immunoassays are reasonably accurate in detecting "normal" male testosterone levels, they are less sensitive at lower levels. MS may offer a more sensitive assay, albeit at a higher cost. It is likely that technology will continue to advance to ultimately provide a serum testosterone assay with excellent sensitivity and specificity, as well ease of use and high-throughput capacity. An example of such advancements is the current generation of thyroid-stimulating hormone assays, which offer excellent sensitivity and large dynamic range and the common use free thyroxine in thyroid screening. In the interim, it is imperative for clinicians to know and understand the specific serum testosterone assay being used by their respective laboratory. Equally important is the communication between the clinician and laboratory staff to ensure the diagnostic requirements can be achieved and maintained using the existing diagnostic instrument.

With newer methods of testosterone detection, $0.7 \mathrm{nmol} / \mathrm{L}$ has been raised as a more appropriate benchmark for castrate testosterone levels than the current benchmark of $1.7 \mathrm{nmol} / \mathrm{L}$; however, even with the higher benchmark, some patients on $\mathrm{LHRH}$ agonists are not achieving castrate testosterone levels.

Competing interests: Dr. Pouliot has been an advisor for Amgen, Astellas, and Pfizer; a speaker for Sanofi; and has received payment/grants/honoraria from Amgen, Astellas, AstraZeneca, Janssen,

B

What is the lower limit of testosterone detection in your centre/lab?

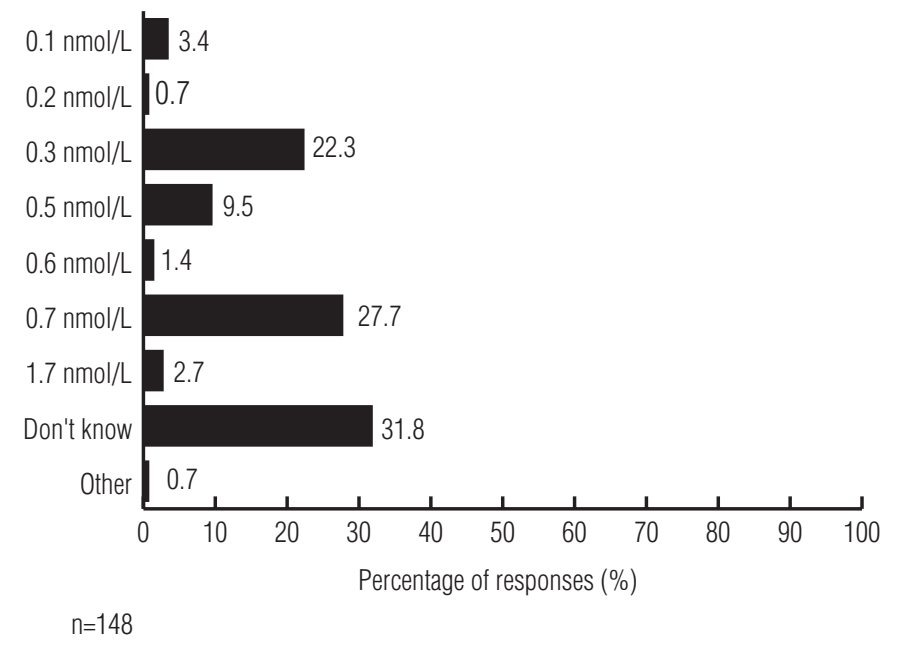

Fig. 3. (A)Types; and (B) lower limit of testosterone detection of testosterone monitoring assays used among Canadian urologists, radiation oncologists, and urooncologists. 
Pfizer, and Sanofi. Dr. So has been a speaker for Amgen, Astellas, and Janssen. The remaining authors report no competing personal or financial interests.

This paper has been peer-reviewed.

\section{References}

1. Huggins C, Hodges CV. Studies on prostatic cancer: I. The effect of castration, of estrogen, and of androgen injection on serum phosphatases in metastatic carcinoma of the prostate. Cancer Res 1941;1:293-7.

2. Tombal B, Berges R. How good do current LHRH agonists control testosterone? Can this be improved with Eligard? Eur Urol 2005;4:30-6. https://doi.org/10.1016/i.eursup.2005.08.004

3. Burger $H G$, Kent JR, Kellie AE. Determination of testosterone in human peripheral and adrenal venous plasma. J Clin Endocrinol Metab 1964;24:432-41. https://doi.org/10.1210/icem-24-5-432

4. Oefelein MG, Feng A, Scolieri MJ, et al. Reassessment of the definition of castrate levels of testosterone: Implications for clinical decision-making. Urology 2000;56:1021-4. https://doi.org/10.1016/S00904295(00)00793-7

5. Wilke TJ, Utley DJ. Total testosterone, free-androgen index, calculated free testosterone, and free testosterone by analog RIA compared in hirsute women and in otherwise normal women with altered binding of sex hormone-binding globulin. Clin Chem 1987;33:1372-5

6. Nishiyama T. Serum testosterone levels after medical or surgical androgen deprivation: A comprehensive review of the literature. Urol Oncol 2014;32:38.e17-28. https://doi.org/10.1016/i.urolonc.2013.03.007

7. Kaisary AV, Tyrrell CJ, Peeling WB, et al. Comparison of LHRH analogue (Zoladex) with orchiectomy in patients with metastatic prostatic carcinoma. Br J Urol 1991;67:502-8. https://doi.org/10.1111/i.1464410X.1991.tb15195.x

8. Lin BJ, Chen KK, Chen MT, et al. The time for serum testosterone to reach castrate level after bilateral orchiectomy or oral estrogen in the management of metastatic prostatic cancer. Urology 1994;43:834-7. https://doi.org/10.1016/0090-4295(94)90145-7

9. Vogelzang NJ, Chodak GW, Soloway MS, et al. Goserelin vs. orchiectomy in the treatment of advanced prostate cancer: Final results of a randomized trial. Zoladex Prostate Study Group. Urology 1995;46:220-6. https://doi.org/10.1016/S0090-4295(99)80197-6

10. Veldhuis JD, Liem AY, South S, et al. Differential impact of age, sex steroid hormones, and obesity on basal vs. pulsatile growth hormone secretion in men as assessed in an ultrasensitive chemiluminescence assay. J Clin Endocrinol Metab 1995;80:3209-22. https://doi.org/10.1210/icem.80.11.7593428

11. Ongarello $S$, Steiner E, Feverstein I, et al. Integration of tPSA and high-throughput mass spectrometry data improves prostate cancer prediction. Eur Urol 2007;6:150. https://doi.org/10.1016/S1569$9056(07) 60507-7$

12. Røhl HF, Beuke HP. Effect of orchidectomy on serum concentrations of testosterone and dihydrotestosterone in patients with prostatic cancer. Scand J Urol Nephrol 1992;26:11-43. https://doi.org/10.3109/00365599209180389

13. Morote J, Orsola A, Planas J, et al. Redefining clinically significant castration levels in patients with prostate cancer receiving continuous androgen-deprivation therapy. J Urol 2007;178:1290-5. https://doi.org/10.1016/i.juro.2007.05.129

14. Zlotta A, Debruyne FMJ. Expert opinion on optimal testosterone control in prostate cancer. Eur Urol 2005;4:37-41. https://doi.org/10.1016/i.eursup.2005.08.005

15. National Comprehensive Cancer Network (NCCN). NCCN Clinical Practice Guidelines in Oncology. Prostate Cancer. Version 2.2016.

16. Mottet N, Bellmunt J, Briers E, et al. Guidelines on prostate cancer. Update March 2016. European Association of Urology. Available at htrps://uroweb.org/wp-content/uploads/EAU-Guidelines-ProstateCancer-2016.pdf. Accessed May 6, 2017.

17. Loblaw DA, Virgo KS, Nam R, et al; American Society of Clinical Oncology. Initial hormonal management of androgen-sensitive metastatic, recurrent, or progressive prostate cancer: 2006 update of an American Society of Clinical Oncology practice guideline. J Clin Oncol 2007;25:1596-605. https://doi.org/10.1200/JC0.2006.10.1949

18. Saad F, Chi KN, Finelli A, et al. The 2015 CUA-CUOG guidelines for the management of castration-resistant prostate cancer (CRPC). Can Urol Assoc J 2015;9:90-6. https://doi.org/10.5489/cuaj.2526

19. Morote J, Esquena $S$, Abascal JM, et al. Failure to maintain a suppressed level of serum testosterone during long-acting depot luteinizing hormone-releasing hormone agonist therapy in patients with advanced prostate cancer. Urol Int 2006;77:135-8. https://doi.org/10.1159/000093907

20. Oefelein MG, Cornum R. Failure to achieve castrate levels of testosterone during luteinizing hormonereleasing hormone agonist therapy: The case for monitoring serum testosterone and a treatment decision algorithm. J Urol 2000;164:726-9. https://doi.org/10.1016/S0022-5347(05)67290-4
21. Wechsel HW, Zerbib M, Pagano F, et al. Randomized, open-labelled comparative study of the efficacy, safety, and tolerability of leuprorelin acetate $1 \mathrm{M}$ and $3 \mathrm{M}$ depot in patients with advanced prostatic cancer. Eur Urol 1996;30:7-14.

22. McLeod D, Zinner N, Tomera K, et al. A phase 3 , multicentre, open-label, randomized study of abarelix vs. leuprolide acetate in men with prostate cancer. Urology 2001;58:756-61. https://doi.org/10.1016/ S0090-4295(01)01342-5

23. Kawakami J, Morales A. Clinical significance of suboptimal hormonal levels in men with prostate cancer treated with LHRH agonists. Can Urol Assoc J 2013;7:E226-30. https://doi.org/10.5489/cuaj.540

24. Niazi T, Bahoric B, Azoulay L, et al. Testosterone breakthrough during luteinizing hormone-releasing hormone agonist therapy impacts biochemical disease progression: Fact or myth? Int I Radiat Oncol Biol Phys 2013;87:S155.

25. Pickles T, Hamm J, Morris WJ, et al. Incomplete testosterone suppression with luteinizing hormone-releasing hormone agonists: Does it happen and does it matter? BJU Int 2012;110:E500-7. https://doi.org/10.1111/j.1464-410X.2012.11190.x

26. Pickles T, Schreiber W, Tyldesley $S$, et al. How often do breakthroughs of testosterone suppression occur while on an LHRH analogue (LHRHa), and are they of importance? J Urol 2011;185:e143-4. https://doi.org/10.1016/i.juro.2011.02.438

27. Pickles T, Tyldesley S. Testosterone breakthrough during LHRH agonist androgen deprivation with curative radiation: Impact on PSA kinetics and subsequent biochemical outcomes. Eur Urol 2011;10:239.

28. Dason S, Allard CB, Tong J, et al. Defining a new testosterone threshold for medical castration: Results from a prospective cohort series. Can Urol Assoc J 2013;7:E263-7. https://doi.org/10.5489/cuaj.471

29. Crook JM, $O^{\prime}$ Callaghan CJ, Duncan $G$, et al. Intermittent androgen suppression for rising PSA level after radiotherapy. N Engl J Med 2012;367:895-903. https://doi.org/10.1056/NEJMoal201546

30. Klotz L, $O^{\prime}$ Callaghan C, Ding K, et al. Nadir testosterone with first year of androgen-deprivation therapy predicts for time to castration-resistant progression: A secondary analysis of the PR-7 trial of intermittent vs. continuous ADT. J Clin Oncol 2015;33:1151-6. https://doi.org/10.1200/JC0.2014.58.2973

31. Tombal B, Cornel E, Matveev V, et al. Clinical outcomes and testosterone levels following continuous androgen deprivation (CAD) in patients with relapsing or locally advanced prostate cancer (PC): A post-hoc analysis of the ICELAND study. Ann Oncol 2016;27:742P. https://doi.org/10.1093/annonc/mdw372.26

32. Wang Y, Dai B, Ye DW. Serum testosterone level predicts the effective time of androgen-deprivation therapy in metastatic prostate cancer patients. Asian J Androl 2016. [Epub ahead of print].

33. Bertaglia $V$, Tucci $M$, Fiori $C$, et al. Effects of serum testosterone levels after 6 months of androgen-deprivation therapy on the outcome of patients with prostate cancer. Clin Genitourin Cancer 2013;11:325-30. https://doi.org/10.1016/i.llgc.2013.01.002

34. de Bono IS, Logothetis $\mathrm{CJ}$, Molina A, et al. Abiraterone and increased survival in metastatic prostate cancer. N Engl J Med 2011;364:1995-2005. https://doi.org/10.1056/NEJMoa1014618

35. Ryan CJ, Molina A, Li J, et al. Serum androgens as prognostic biomarkers in castration-resistant prostate cancer: Results from an analysis of a randomized, phase 3 trial. J Clin Oncol 2013;31:2791-8. https://doi.org/10.1200/JC0.2012.45.4595

36. Shiota $M$, Fujimoto N, Yokomizo A, et al. The prognostic impact of serum testosterone during androgendeprivation therapy in patients with metastatic prostate cancer and the SRD5A2 polymorphism. Prostate Cancer Prostatic Dis 2016;19:191-6. https://doi.org/10.1038/pcan.2016.2

37. Herati AS, Cengiz C, Lamb DJ. Assays of serum testosterone. Urol Clin N Am 2016;43:177-84. https://doi.org/10.1016/i.ucl.2016.01.003

38. Krasowski MD, Drees D, Morris CS, et al. Cross-reactivity of steroid hormone immunoassays: Clinical significance and two-dimensional molecular similarity prediction. BMC Clin Pathol 2014;14:33. https://doi.org/10.1186/1472-6890-14-33

39. Zendjabil M, Chellouai Z, Abbou 0. Role of mass spectrometry in steroid assays. Ann Endocrinol 2016;77:43-8. https://doi.org/10.1016/i.ando.2016.01.004

Correspondence: Dr. Bobby Shayegan, Division of Urology, Department of Surgery, McMaster University, Hamilton, 0N, Canada; shayeb@mcmaster.ca

To answer the three multiple-choice questions associated with this review article, go to: https://www.qzzr.com/c/quiz/417864/claim-section-3-self-assessment-credits-for-readingcuaj-06-17

This program is an Accredited Self-Assessment Program (Section 3) as defined by the Maintenance of Cerrification Program of The Royal College of Physicians \& Surgeons of Canada, and approved by the Canadian Urological Association. Remember to visit MAINPORT (www.mainport.org/ mainport/) to record your learning and outcomes. You may claim a maximum of 1 hour of credit. 